\title{
Percent body fat estimations in college men using field and laboratory methods: A three-compartment model approach Jordan R Moon ${ }^{1}$, Sarah E Tobkin ${ }^{1}$, Abbie E Smith1, Michael D Roberts ${ }^{3}$, Eric D Ryan ${ }^{2}$, Vincent J Dalbo ${ }^{3}$, Chris M Lockwood ${ }^{1}$, Ashley A Walter ${ }^{2}$, Joel T Cramer ${ }^{2}$, Travis W Beck ${ }^{2}$ and Jeffrey R Stout*1
}

Address: ${ }^{1}$ Department of Health and Exercise Science, Metabolic and body composition laboratories, University of Oklahoma, Norman, OK, USA, ${ }^{2}$ Department of Health and Exercise Science, Biophysics laboratory, University of Oklahoma, Norman, OK, USA and ${ }^{3}$ Department of Health and Exercise Science, Applied biochemistry and molecular physiology laboratory, University of Oklahoma, Norman, OK, USA

Email: Jordan R Moon - jordanmoon@ou.edu; Sarah E Tobkin - sarahtobkin@ou.edu; Abbie E Smith - abbiesmith@ou.edu; Michael D Roberts - mike_roberts@ou.edu; Eric D Ryan - eryan@ou.edu; Vincent J Dalbo - vinnyjames@ou.edu;

Chris M Lockwood - chrislockwood@ou.edu; Ashley A Walter - ashannwalter@ou.edu; Joel T Cramer - jcramer@ou.edu; Travis W Beck - tbeck@ou.edu; Jeffrey R Stout* - jrstout@ou.edu

* Corresponding author

Published: 21 April 2008

Dynamic Medicine 2008, 7:7 doi:10.1186/1476-5918-7-7
Received: 14 March 2008

Accepted: 21 April 2008

This article is available from: http://www.dynamic-med.com/content/7/1/7

(c) 2008 Moon et al; licensee BioMed Central Ltd.

This is an Open Access article distributed under the terms of the Creative Commons Attribution License (http://creativecommons.org/licenses/by/2.0), which permits unrestricted use, distribution, and reproduction in any medium, provided the original work is properly cited.

\begin{abstract}
Background: Methods used to estimate percent body fat can be classified as a laboratory or field technique. However, the validity of these methods compared to multiple-compartment models has not been fully established. The purpose of this study was to determine the validity of field and laboratory methods for estimating percent fat (\%fat) in healthy college-age men compared to the Siri three-compartment model (3C).

Methods: Thirty-one Caucasian men $(22.5 \pm 2.7 \mathrm{yrs} ; 175.6 \pm 6.3 \mathrm{~cm} ; 76.4 \pm 10.3 \mathrm{~kg})$ had their \%fat estimated by bioelectrical impedance analysis (BIA) using the BodyGram ${ }^{\mathrm{TM}}$ computer program (BIA-AK) and population-specific equation (BIA-Lohman), near-infrared interactance (NIR) (Futrex $\left.{ }^{\circledR} 6 / 00 / X L\right)$, four circumference-based military equations [Marine Corps (MC), Navy and Air Force (NAF), Army (A), and Friedl], air-displacement plethysmography (BP), and hydrostatic weighing (HW).

Results: All circumference-based military equations $(\mathrm{MC}=4.7 \% \mathrm{fat}, \mathrm{NAF}=5.2 \% \mathrm{fat}, \mathrm{A}=4.7 \% \mathrm{fat}$, Friedl $=4.7 \%$ fat $)$ along with NIR $(N I R=5.1 \%$ fat $)$ produced an unacceptable total error $(T E)$. Both laboratory methods produced acceptable $T E$ values ( $\mathrm{HW}=2.5 \%$ fat; $\mathrm{BP}=2.7 \%$ fat). The BIA-AK, and BIA-Lohman field methods produced acceptable TE values (2.I\% fat). A significant difference was observed for the MC and NAF equations compared to both the $3 C$ model and HW $(p<0.006)$.

Conclusion: Results indicate that the BP and HW are valid laboratory methods when compared to the $3 \mathrm{C}$ model to estimate \%fat in college-age Caucasian men. When the use of a laboratory method is not feasible, BIA-AK, and BIA-Lohman are acceptable field methods to estimate \%fat in this population.
\end{abstract}




\section{Background}

Accurate assessment of body composition is necessary in order to monitor obesity class, nutritional status, training outcomes, and general health [1]. Validated laboratory methods, such as hydrostatic weighing (HW), and multiple compartment models, like the three-compartment (3C) model, are impractical to use in large population studies. Specifically, Wang et al. [2] concluded that the 3C model of Siri [3] was superior to HW using the Brozek et al. [4] equation to estimate percent body fat (\%fat) when compared to the six-compartment model, while Fuller et al. [5] determined that the precision between the fourcompartment (4C) and 3C model did not differ. However, some discrepancy exists when comparing HW to the multiple-compartment model in adult men $[2,6]$. Nonetheless, both multiple-compartment models and HW entail greater facility requirements and are more costly compared to more convenient field methods, such as anthropometric equations, near-infrared interactance (NIR), and bioelectrical impedance analysis (BIA).

When assessing body composition, NIR and BIA are appealing field methods due to the safety, noninvasiveness, and speed of administration when compared to laboratory techniques that require some risk, expensive equipment, and trained personnel [7]. An alternative field method to NIR and BIA is the use of anthropometric measurements to estimate body density (BD) and \%fat. Currently, the United States Military uses circumference measurements to estimate the \%fat of soldiers and recruits. Specifically, three equations using neck and waist circumferences were developed based on HW for the Marine Corps (MC), Navy and Air Force (NAF), and the Army (A). In 1997, Friedl and Vogel [8] cross-validated these three equations with dual-energy X-ray absorptiometry (DXA) and developed a new equation (Friedl) based on their findings. However, no one has validated these equations for estimating \%fat against a multi-compartment criterion method. Nonetheless, if the use of military circumference-based equations is valid for estimating $\%$ fat in college-age men, then this could be another rapid and non-invasive method of determining \%fat. Therefore, if acceptable agreement is found to exist between established laboratory methods, like the 3C model and field methods, such as NIR, BIA, and circumference-based equations, these field methods could provide potential alternatives to cumbersome laboratory methods.

The purpose of this study was to compare \%fat estimations between laboratory methods [Air Displacement Plethysmography via the BOD $\operatorname{POD}^{\circledast}(\mathrm{BP})$ and $\mathrm{HW}$, newly unvalidated methods and devices (NIR (Futrex ${ }^{\circledR}$ 6100/XL), BIA-AK (RJL Quantum II)), military circumference-based equations and the population-specific BIA-
Lohman equation to the $3 \mathrm{C}$ model \%fat values in collegeage Caucasian men.

\section{Methods \\ Participants}

Thirty-one Caucasian men volunteered to participate in the study (Table 1). All body composition measurements were performed on the same day following a 12-hour fast (ad libitum water intake was allowed). HW was performed last while all prior body composition measurements were performed in no particular order. The subjects were also instructed to refrain from exercising for at least 12 hours prior to testing. The purpose of the study and a description of the testing protocol were explained to each subject. Additionally, the study was approved by The Institutional Review Board for Human Subjects. Written informed consent was obtained from each subject prior to testing.

\section{Hydrostatic Weighing}

Body density (BD) was assessed from HW as previously described by our laboratory and others $[2,6,9,10]$. Residual volume was determined with the subject in a seated position using the oxygen dilution method of Wilmore et al. [11] via a metabolic cart with residual volume software (True One $2400^{\circledR}$, Parvo-Medics, Inc. Provo, Utah). Subjects completed a minimum of two trials and the average of the closest two trials within 5\% was used to represent residual volume.

Underwater weight was measured to the nearest $0.025 \mathrm{~kg}$ in a submersion tank in which a PVC swing seat was suspended from a calibrated Chatillon ${ }^{\circledR} 15$-kg scale (Model \# $1315 \mathrm{DD}-\mathrm{H}$, Largo, Florida). The average of the three highest values ( 6 to 10 trials) was used as the representative underwater weight. Percent body fat was calculated using the revised formula of Brozek et al[4]. Previous test-retest reliability data for HW from our laboratory indicated that, for 11 young adults $(24 \pm 2.4 \mathrm{yr})$ measured on separate days, the ICC was 0.99 with a SEM of $0.8 \%$ fat and $0.002729 \mathrm{~g} \cdot \mathrm{cc}^{-1}$ for BD.

\section{Air Displacement Plethysmography (BOD POD ${ }^{\circledR}$ )}

Before each test, the BP was calibrated according to the manufacturer's instructions with the chamber empty using a cylinder of known volume (49.558 L). The subject, wearing tight fitting compression shorts and a swimming cap, entered and sat in the fiberglass chamber. The BP was sealed, and the subject breathed normally for 20 seconds while body volume was measured. Next, the subject was connected to a breathing tube internal to the system to measure thoracic gas volume. The subject resumed tidal breathing cycles; a valve in the circuit caused a momentary occlusion of the airway, during which the subject gently "puffed". This effort produced small pressure fluctuations in the airway and chamber that were used to determine 
Table I: Description characteristics of the subjects $(n=31)$

\begin{tabular}{lllc}
\hline \multicolumn{1}{c}{ Variable } & & SD & Range \\
& \multicolumn{1}{c}{$x$} & & \\
\hline Age $(\mathrm{y})$ & 22.5 & 2.7 & $18-33$ \\
Body mass $(\mathrm{kg})$ & 76.4 & 10.3 & $56.88-101.7$ \\
Height $(\mathrm{cm})$ & 175.6 & 6.3 & $165.8-191.3$ \\
Abdominal $(\mathrm{cm})$ & 81.3 & 7.7 & $69.4-105.5$ \\
Neck $(\mathrm{cm})$ & 38.0 & 2.2 & $34.7-42.7$ \\
BMI & 24.8 & 3.1 & $20.0-31.9$
\end{tabular}

thoracic gas volume. This value was used to correct body volume for thoracic gas volume and percent body fat was calculated from BD using the revised formula of Brozek et al[4]. All BP measurements were performed by a BOD POD $^{\oplus}$-certified investigator who had previously demonstrated a SEM of $0.48 \%$ fat.

\section{Near-Infrared Interactance}

The Futrex ${ }^{\circledast} 6100 / \mathrm{XL}$ was used to measure the $\%$ fat of each subject according to the procedures recommended by the manufacturer (Futrex ${ }^{\otimes}$, Hagerstown, MD). This device emits infrared light of six specific wavelengths $(810,910$, $932,944,976$, and 1,023 nm) into the anterior midline of the biceps brachii midway between the antecubital fossa and acromion process of the right arm. A silicon-based detector then measures the intensity of the re-emitted light, which is expressed as optical density. Percent body fat was estimated using a pre-programmed generalized multiple regression equation that included height, weight, and optical density values. The specific equation used to calculate \%fat was not available from the manufacturer. The instrument was calibrated prior to each measurement with the manufacturer-supplied optical standard. Previous test-retest measurements for the Futrex ${ }^{\circledast} 6100 /$ XL produced a SEM of $0.74 \%$ fat.

\section{Bioelectrical Impedance Analysis}

BIA analysis was performed using the Quantum II Bioelectrical Body Composition Analyzer following the procedures recommended by the manufacturer (RJL Systems, Clinton Twp, MI). Percent body fat was estimated from the resistance $(\Omega)$ and reactance $(\Omega)$ values produced by the Quantum II. Briefly, after resting in a supine position for 5 to 10 minutes, resistance and reactance measurements were taken while the subjects lay supine on a table with their arms $\geq 30$ degrees away from their torso with their legs separated. Electrodes were placed at the distal ends of the subject's right hand and foot following the manufacturer guidelines. Excess body hair was removed prior to electrode placement. The site (skin) was cleaned with alcohol. The average of two trials within $\pm 5 \Omega$ was used to represent the subject's resistance $(\mathrm{Rz})$ and reactance $(\mathrm{Xc})$ values. The average of resistance values and the subject's height, weight, sex, and age were entered into a computer program (BodyGram ${ }^{\mathrm{TM}}$ Version 1.31, Akern Bioresearch, Pontassieve (Florence), Italy) to estimate $\%$ fat (BIA-AK). Additionally, fat free mass was estimated from Lohman's [12] prediction equation (BIA-Lohman) specific to this population and converted to \%fat (Table $2)$. Previous test-retest measurements for BIA-AK produced a $S E M$ of $0.68 \%$ fat.

\section{Bioimpedance Spectroscopy}

Bioimpedance spectroscopy (BIS) was used to estimate total body water (TBW) following the procedures recommended by the manufacturer (Imp ${ }^{\mathrm{TM}}$ SFB7, ImpediMed Limited, Queensland, Australia). This technique, explained elsewhere [13], uses a range of frequencies, encompassing both low and high ranges that allow electrical current to pass around and through each cell, and has produced valid estimates of TBW when compared to a criterion method, such as deuterium oxide $[9,13,14]$. Results from our laboratory have also shown that the BIS device used in the current investigation is a valid measurement tool for determining TBW when compared to deuterium oxide [15]. Furthermore, BIS has been used to assess TBW for multi-compartment equations in previous validation studies $[9,16,17]$. TBW measurements were taken while the subject lay supine on a table with their arms $\leq$ $30^{\circ}$ away from the torso and legs separated. Electrodes were placed at the distal ends of each subject's right hand and foot following the manufacturer's guidelines. Prior to electrode placement, excess body hair was removed, and the skin was cleaned with alcohol at each site. The average of two trials within $\pm 0.05 \mathrm{~L}$ was used as the representative TBW. Prior to analysis, each subject's height (HT), body mass (BM), age, and sex were entered into the BIS device. The BIS utilized 256 frequencies internal to the device to estimate TBW. Previous test-retest measurements of 11 men and women measured 24 to $48 \mathrm{hr}$ apart for TBW using the Imp ${ }^{\mathrm{TM}}$ SFB7 BIS produced a SEM of $0.48 \mathrm{~L}$.

\section{Circumference measurements}

Circumference measurements were taken with a Gulick II measuring tape by an investigator who had previously demonstrated a test-retest reliability of $r>0.90$. Measurements were taken according to the recommendations of Friedl and Vogel [8] at the abdomen (AB) and neck (N). Two measurements within $1 \%$ were used to represent $A B$ and $\mathrm{N}$ circumferences. The following equations were used to estimate \%fat:

MC - Marine Corps [18] $=(0.740 \times \mathrm{AB})-(1.249 \times \mathrm{N})+$ 0.985

A - Army $[19]=[76.5 \times \log (\mathrm{AB}-\mathrm{N})]-(68.7 \times \log \mathrm{HT})+$ 43.7 
Table 2: Validation of methods of predicting \% body fat compared to the $3 \mathrm{C}$ model

\begin{tabular}{|c|c|c|c|c|c|c|c|c|c|}
\hline & Method & $\%$ fat $(\bar{x} \pm \mathrm{SD})$ & Slope & Intercept & $C E$ & $r$ & SEE & $T E$ & Limits \\
\hline & $3 C$ & $16.3 \pm 4.7$ & & & & & & & \\
\hline \multirow[t]{7}{*}{ Field } & $M C$ & $13.6 \pm 4.1$ & 0.71 & 6.71 & $2.69^{*}$ & 0.62 & 3.78 & $4.7 \dagger$ & $5.00,-10.38$ \\
\hline & NAF & $13.4 \pm 4.9$ & 0.55 & 8.86 & $2.86^{*}$ & 0.57 & 3.96 & $5.2 \dagger$ & $5.87,-11.60$ \\
\hline & $A$ & $14.3 \pm 4.4$ & 0.60 & 7.68 & 1.96 & 0.57 & 3.97 & $4.7 \dagger$ & $6.44,-10.36$ \\
\hline & Friedl & $14.4 \pm 4.7$ & 0.57 & 8.01 & 1.86 & 0.57 & 3.94 & $4.7^{\dagger}$ & $6.69,-10.42$ \\
\hline & NIR & $14.3 \pm 4.6$ & 0.50 & 9.16 & 1.98 & 0.49 & 4.20 & $5.1 t$ & $7.30,-11.27$ \\
\hline & BIA-AK & $17.1 \pm 4.5$ & 0.95 & 0.05 & -0.78 & 0.91 & 2.00 & 2.1 & $4.65,-3.09$ \\
\hline & BIA-Lohman & $16.0 \pm 4.0$ & 1.07 & -0.74 & 0.33 & 0.90 & 2.14 & 2.1 & $3.83,-4.48$ \\
\hline \multirow[t]{2}{*}{ Lab } & BP & $16.3 \pm 5.5$ & 0.75 & 4.12 & 0.04 & 0.86 & 2.42 & 2.7 & $5.35,-5.43$ \\
\hline & $\mathrm{HW}$ & $15.8 \pm 4.7$ & 0.87 & 2.51 & 0.53 & 0.86 & 2.44 & 2.5 & $4.31,-5.36$ \\
\hline
\end{tabular}

\footnotetext{
* Represents significance $(p<0.0055)$, † Represents an unacceptable TE $(T E>4.0 \% \mathrm{BF})$

$C E=$ Constant error, $T E=$ Total error, $S E E=$ Standard error of estimate, $r=$ Pearson product-moment correlation coefficient, Limits $=95 \%$ limits of agreement ( $C E \pm 1.96 \mathrm{SD}$ of residual scores (predicted-actual))

$\%$ Fat $=$ (body mass - fat free mass) $/$ body mass

$3 \mathrm{C} \%$ fat $[3]=[(2.118 /$ body density $)-[0.78 \times($ total body water in L/body mass in $\mathrm{kg})]-1.354] \times 100$

$M C$ - Marine Corps [18], \%fat $=(0.740 \times$ abdominal circumference in $\mathrm{cm})-(1.249 \times$ neck circumference in $\mathrm{cm})+0.985$

NAF - Navy and Air Force [2I], \% fat $=[(4.95 /$ body density $)-4.5] \times 100$

$\operatorname{NAF}[20]$, body density $=[0.155 \times \log ($ height in $\mathrm{cm})]-[0.191 \times \log ($ abdominal - neck circumference in $\mathrm{cm})]+1.032$

Army [19], \%fat $=[76.5 \times \log ($ abdominal - neck circumference in $\mathrm{cm})]-[68.7 \times \log ($ height in $\mathrm{cm})]+43.7$

Friedl [8], \%fat $=[0.77 \mathrm{I} \times($ abdominal - neck circumference in $\mathrm{cm})]-(0.132 \times$ height in $\mathrm{cm})+4.29$

$N I R=$ Near-infrared interactance $($ Futrex 6/00/XL)

$\mathrm{BIA}=$ Bioelectrical impedance analysis (RJL Systems Quantum II)

$\mathrm{AK}=$ Computer-generated from BodyGram ${ }^{\mathrm{TM}}$ Version I.3I (Akern Bioresearch)

Lohman [12], fat free mass $(\mathrm{kg})=\left[0.485 \times\left(\right.\right.$ height in $\mathrm{cm}^{2} /$ resistance in $\left.\left.\Omega\right)\right]+[0.338 \times($ body mass in $\mathrm{kg})]+5.32$

$\mathrm{BP}=$ BOD POD ${ }^{\circledR}[4], \%$ fat $=[(4.57 /$ body density $)-4.142] \times 100$

$\mathrm{HW}=$ Hydrostatic weighing $[4], \% \mathrm{fat}=[(4.57 /$ body density $)-4.142] \times 100$
}

Friedl $[8]=[0.771 \times(\mathrm{AB}-\mathrm{N})]-(0.132 \times \mathrm{HT})+4.29$

Body Density and \%fat values for the NAF equation were calculated with the following equations:

NAF - Navy and Air Force [20]

$\mathrm{BD}=(0.155 \times \log \mathrm{HT})-[0.191 \times \log (\mathrm{AB}-\mathrm{N})]+1.032$

$\%$ fat $[21]=[(4.95 / \mathrm{BD})-4.5] \times 100$

\section{C Calculation}

The following equation was used to calculate the criterion \%fat via the 3C model [3]:

$\%$ fat $=[(2.118 / \mathrm{BD})-(0.78 \times$ TBW/Body Mass $(\mathrm{kg}))-$ $1.354] \times 100$

The total error of measurement TEM for the 3C model was calculated from the following equation [22]:

$$
\begin{aligned}
& \text { 3C TEM }=\left(\text { TBW SEM }+ \text { HW BD SEM }{ }^{2}\right)^{1 / 2} \\
& 3 \text { C TEM }=\left(0.48^{2}+0.002729^{2}\right)^{1 / 2}
\end{aligned}
$$

3C $T E M=0.1152 \%$ fat

\section{Data analysis}

Validity of \%fat estimates (BP, HW, NIR, BIA-AK, BIALohman, MC, NAF, A, and Friedl) was based on an evaluation of predicted values versus the criterion (actual) value from $3 \mathrm{C}$ by calculating the constant error $(C E=$ actual (3C) - predicted \%fat), $r$ value, standard error of estimate $\left(S E E=S D \sqrt{1-r^{2}}\right)$ and total error $\left(T E=\sqrt{\left.\sum \text { [predicted - actual }\right]^{2} / \mathrm{n}}\right)$ [7]. The mean difference (CE) between the predicted (BP, HW, NIR, BIA-AK, BIA-Lohman, MC, NAF, A, and Friedl) and actual (3C) $\%$ fat values was analyzed using dependent t-tests with the Bonferroni alpha adjustment ( $p \leq 0.0055)$ [23]. Additionally, the method of Bland and Altman was used to identify the 95\% limits of agreement between the criterion and predicted \%fat values [24].

\section{Results}

The 3C model was considered the criterion measure. The average \%fat determined by the $3 \mathrm{C}$ was $16.3 \pm 4.7 \%$ fat. Presented in Table 2 are the results of the validation anal- 
yses. Constant error values ranged from 2.86 (NAF) to 0.04 (BP) with significant $C E$ differences $(p \leq 0.005)$ detected for MC and NAF. The lowest validity coefficient was 0.49 (NIR) and the highest was 0.91 (BIA-AK), while the SEE values ranged from $2.00 \%$ fat (BIA-AK) to $4.20 \%$ fat (NIR). All laboratory methods resulted in acceptable $T E$ values $(\leq 2.7 \%$ fat). Both BIA (BIA-AK, BIA-Lohman) field methods resulted in acceptable $T E$ values $(\leq 2.1 \%$ fat), while all military circumference-based equations (MC, NAF, A, Friedl) and NIR resulted in unacceptable TE values ( $\geq 4.7 \%$ fat). Additionally, compared to HW (Table $3)$, the MC, A, and Friedl, military circumference-based equations produced large but acceptable TE values ( $\geq$ $3.5 \%$ fat and $<4.0 \%$ fat). Of the field methods, the $95 \%$ limits of agreement were the largest for all circumferencebased equations and NIR ( $\geq 5.00$ to $-10.36 \%$ fat), while the BIA-AK and BIA-Lohman produced smaller limits of agreement ( $\leq 4.65$ to $-4.48 \%$ fat $)$.

\section{Discussion}

Both laboratory methods (HW, BP) used to estimate body composition in this study produced acceptable TE values ( $\leq 4 \%$ fat), while only the BIA (BIA-AK, BIA-Lohman) methods resulted in acceptable TEvalues $(\leq 4 \%$ fat $)$ and are acceptable for estimating \%fat in college-age Caucasian men. The four military circumferences-based equations (MC, NAF, A, Friedl) and NIR produced unacceptable $T E$ values ( $\geq 4.7 \%$ fat) compared to the $3 \mathrm{C}$ model. Additionally, the NIR was the only method to produce both unacceptable TE, and SEE values ( $\geq 4.2 \%$ fat).

\section{Laboratory Methods}

Hydrostatic Weighing

Contrary to the findings of Clasey et al. [6], who compared HW to a $4 \mathrm{C}$ model ( $T E=5.8 \%$ fat) in young men, HW produced acceptable $T E$ values $(T E=2.5 \%)$ in the young men in this study. However, in agreement with Clasey et al. [6], HW produced a similar $r$ value $(r=0.85)$ and a non-significant $C E$ ( $C E=0.90 \%$ fat $)$ compared to the current findings ( $r=0.86, C E=0.53 \%$ fat). The discrepancies of these findings could be a result of the two-compartment (2C) model used. Clasey et al. [6] used the $2 \mathrm{C}$ model of Siri [21], while the current investigation used the Brozek et al. [4] 2C model. Additionally, Visser et al. [25] used the Siri [21] 2C model and found the difference in $\%$ fat values from $\mathrm{HW}$ and the $4 \mathrm{C}$ to be non-significant and $<2 \%$ fat. However, Withers et al. [26] used the Brozek et al. [4] equation used in the current study and found a greater $C E(2.2 \%$ fat $)$ than the current investigation $(C E=$ $0.53 \%$ ) compared to the $3 \mathrm{C}$ model in both trained and sedentary males. Nonetheless, all three studies concluded that the use of multiple-compartment models that included TBW was more accurate than HW for estimating $\%$ fat in men. It appears from the current investigation HW is a valid method for estimating \%fat in this population. However, the 95\% limits of agreement suggest HW may over-predict \%fat by as much as $5.36 \%$ fat and under-predict by as much as $4.31 \%$ fat. These individual variations are most likely due to the use of a $2 \mathrm{C}$ model which does not require an estimate of TBW. Therefore, caution should be used when relying on HW alone as a method to identify \%fat in small groups or individuals.

\section{Air-displacement plethysmography (BOD POD $\left.{ }^{\circledR}\right)$}

Due to the ease in procedure, speed, and improved subject compliance, $\mathrm{BP}$ provides an attractive alternative to $\mathrm{HW}$. Additionally, research has shown that participants prefer the BP over HW [27]. Results of this study demonstrated high validity coefficient $(r=0.86)$ and "excellent" SEE (2.42\% fat) and "very good" TE (2.7\% fat) values [7]. Although the BP is a relatively new device, a number of studies have examined the validity when compared to HW in males with contradictory findings [27-30]. However, only limited research is available on the validity of BP in college-age men compared to multiple-compartment models, specifically the $3 \mathrm{C}$ model. Nonetheless, the cur-

Table 3: Validation of methods of predicting \% body fat compared to HW

\begin{tabular}{|c|c|c|c|c|c|c|c|c|}
\hline Method & & $\%$ fat $(\bar{x} \pm \mathrm{SD})$ & Slope & Intercept & $\mathrm{CE}$ & $r$ & SEE & TE \\
\hline HW & & $15.8 \pm 4.7$ & & & & & & \\
\hline \multirow[t]{4}{*}{ Circumference equations } & MC & $13.6 \pm 4.1$ & 0.88 & 3.85 & $2.16 *$ & 0.78 & 3.00 & 3.7 \\
\hline & NAF & $13.4 \pm 4.9$ & 0.71 & 6.24 & $2.34 *$ & 0.74 & 3.20 & 4.1t \\
\hline & A & $14.3 \pm 4.4$ & 0.77 & 4.76 & 1.43 & 0.73 & 3.23 & 3.6 \\
\hline & Friedl & $14.4 \pm 4.7$ & 0.74 & 5.12 & 1.33 & 0.75 & 3.15 & 3.5 \\
\hline
\end{tabular}

* Represents significance $(p<0.0125)$, † Represents an unacceptable TE $(T E>4.0 \% \mathrm{BF})$

$C E=$ Constant error, $T E=$ Total error, $S E E=$ Standard error of estimate, $r=$ Pearson product-moment correlation coefficient.

$\mathrm{HW}=$ Hydrostatic weighing [4], \% fat $=[(4.57 /$ body density $)-4.142] \times 100$

$\mathrm{MC}-$ Marine Corps [18], \%fat $=(0.740 \times$ abdominal circumference in $\mathrm{cm})-(1.249 \times$ neck circumference in $\mathrm{cm})+0.985$

NAF - Navy and Air Force $[21], \%$ fat $=[(4.95 /$ body density $)-4.5] \times 100$

NAF [20], body density $=[0.155 \times \log ($ height in $\mathrm{cm})]-[0.191 \times \log ($ abdominal - neck circumference in $\mathrm{cm})]+1.032$

Army [19], \%fat $=[76.5 \times \log ($ abdominal - neck circumference in $\mathrm{cm})]-[68.7 \times \log ($ height in $\mathrm{cm})]+43.7$

Friedl $[8], \%$ fat $=[0.77 \mathrm{I} \times($ abdominal - neck circumference in $\mathrm{cm})]-(0.132 \times$ height in $\mathrm{cm})+4.29$ 
rent investigation $(S E E=2.42 \%$ fat, $r=0.86)$ produced acceptable values similar to those of McCrory et al. [31] who compared BP (SEE $=1.81 \%$ fat, $r=0.96)$ to HW. To the best of our knowledge, this is the first investigation to compare BP to a multiple-compartment model in collegeage males. The current findings suggest, as with $\mathrm{HW}$, that $\mathrm{BP}$ is a valid method for estimating \%fat in the college-age men. However, the 95\% limits of agreement suggest that BP may over-predict \%fat by as much as 5.43\% and under-predict by as much as $5.35 \%$. These individual variations are most likely due to the use of a $2 \mathrm{C}$ model which does not require an estimate of TBW. Therefore, caution should be used when relying on BP alone as a method to identify \%fat in small groups or individuals.

\section{Field Methods}

Near-Infrared Interactance

The second aim of this study was to examine the validity of the newly-developed NIR device (F6100/XL) employing six wavelengths to estimate \%fat. In 1984, Conway et al. [32] measured infrared wavelengths from 700 to 1100 $\mathrm{nm}$ and determined that the peak absorption of pure fat occurred at $930 \mathrm{~nm}$ and pure water at $970 \mathrm{~nm}$. Based on this research, the Futrex ${ }^{\circledast} 5000 / 1000$ utilized infrared wavelengths at 940 and $950 \mathrm{~nm}$ to measure optical density (OD). However, the updated NIR model used in this investigation (Futrex ${ }^{\circledR}$ 6100/XL) employs six different wavelengths at $810,910,932,944,976$, and $1023 \mathrm{~nm}$ to estimate \%fat [33]. The Futrex ${ }^{\circledast} 6100 /$ XL has advantages over previous models because the wavelengths encompass the same range as in the original research by Conway et al. [32] (700-1100 nm).

Our results indicated the NIR underestimated an average of $1.98 \%$ fat compared to the 3C model. Additionally, the NIR produced unacceptable SEE and TE values $>4.0 \%$ fat. To our knowledge, this is the first complete study to compare the new NIR device to any criterion method. However, other studies have validated earlier models (Futrex ${ }^{\circledR} 5000$ and Futrex ${ }^{\circledR} 1000$ ) in males compared to HW [34-38]. These previous studies concluded that neither the F1000 or F5000 were acceptable methods for estimating $\%$ fat with reported TE or SEE values > 4\% fat [34-38]. In agreement with all of the past literature on NIR and college-age males, the current findings are unacceptable (SEE and $T E$ values $>4.0 \%$ fat). It appears that the six wavelengths utilized in the Futrex ${ }^{\circledR} 6100 / \mathrm{XL}$ compared to the two wavelengths for the Futrex $x^{\circledR} 5000$ and Futrex ${ }^{\circledR} 1000$ did not improve the accuracy for estimating \%fat in this population. The large SEE ( $4.20 \% \mathrm{fat})$ value suggests that the NIR prediction equation has a large individual deviation from the line of best fit, while the low $r(0.49 \%$ fat $)$ value suggests a poor correlation between actual \%fat estimated from the $3 \mathrm{C}$ and from NIR. Regardless of TE, the NIR produced unacceptable SEE (SEE $>4.0 \%$ fat) and $r(r<0.80)$ values. Therefore, the Futrex ${ }^{\circledR} 6100 /$ XL NIR device is not recommended for use in this population. Future research needs to identify the validity of the Futrex ${ }^{\circledast} 6100 /$ XL in various populations.

\section{Bioelectrical Impedance}

Results of previous studies on BIA validity for estimating $\%$ fat in college men have been equivocal [37-45]. Single frequency $(50-\mathrm{kHz})$ BIA devices, such as the RJL Quantum II, are based on the work of Thomasett [46], who implemented the use of a low-level electrical current and measured the opposition of flow. This opposition of electrical current through the body is directly related to its composition of water, fat, and lean tissue. Since the electrolytes in water are good conductors of electric current, the opposition of electrical flow can be used to estimate total body water (TBW) and lean body mass, with the assumption that lean body mass has $\cong 73 \%$ water [47]. Total body mass and lean body mass are used in the calculation of $\%$ fat; however, TBW differences may exist across race, sex, age, and health status. Therefore, body composition experts have suggested using BIA population-specific equations to estimate \%fat $[7,12]$. Lohman [12] developed a population-specific equation for men 18-30 years of age that includes BIA measurement of resistance, height, and weight (BIA-Lohman). A more technical method to assess body composition from BIA uses vectors as described by Piccoli et al. [31] and phase angles as described by Barbosa-Silva and Barros [48], which require BIA-measured resistance and reactance values. The BodyGram $^{\mathrm{TM}}$ (Version 1.31, Akern Bioresearch) computer program utilizes resistance and reactance values to estimate $\%$ fat (BIA-AK) via vectors and phase angles. However, to the best of our knowledge, no research has validated BIAAK \%fat estimations in healthy college-age Caucasian men.

Previous research has compared BIA devices to HW with contrasting results $[37,38,40-45]$. The SEE (2.00\%fat) values reported in this study for BIA-AK (RJL Quantum II, RJL Systems) compared to the $3 \mathrm{C}$ were substantially lower than those reported by other investigators compared to HW $[37,38,40-45]$. The current $r$ value $(r=0.91)$ was greater than most investigations $(r<0.84)[37,40-43,45]$ but similar to the findings of Lukaski et al. [44] $(r=0.93)$. Regarding TE, current BIA-AK results (2.1\%fat) are the lowest reported. Though Eckerson et al. [39] reported acceptable fat free-weight values ( $T E=1.7 \%$ fat $)$, the majority of the literature has reported unacceptable TE values $(T E>4.4)[37,38,40-45]$. These discrepancies are most likely due to the variation of devices used and the subsequent equations or methods used to estimate \%fat. It appears that the current method used to estimate \%fat (BodyGram $^{\mathrm{TM}}$ Version 1.31, Akern Bioresearch) is an 
acceptable procedure to estimate the \%fat of college-age men.

The BIA-Lohman population-specific equation produced similar results to the BIA-AK. Past research has produced similar results to those of the other BIA equations when the BIA-Lohman equation was compared to HW. Eckerson [41] (men $22 \pm 4$ years) found the BIA-Lohman equation to be unacceptable with a TE of $4.4 \%$ fat. However, the current investigation produced an acceptable $T E$ value $(T E=2.1 \%$ fat $)$.

To the best of our knowledge, there has not been an evaluation of the validity of any BIA method of predicting \%fat in college men compared to a multiple-compartment model. Therefore, this is the first investigation showing the strong agreement between the $3 \mathrm{C}$ model or any multiple-component model and both BIA-AK and BIALohman in this population. The lower TE values in the current investigation compared to past literature comparing BIA to $\mathrm{HW}$ are most likely due to the utilization of TBW in the criterion 3C model. The relationship between fat free mass (FFM) and TBW has been well established [47]. The strong correlation between resistance and reactance measured by BIA and FFM measured by BIA could have improved both BIA values in contrast to past literature in which TBW was not estimated. However, in the current investigation, both BIA-AK and BIA-Lohman methods produced larger, but acceptable, TE values compared to HW (BIA-AK, TE $=3.4 \%$ fat; BIA-Lohman, TE = $3.1 \%$ fat), suggesting that TBW may increase the accuracy of BIA procedures. Nonetheless, the removal of TBW in the criterion method did not produce unacceptable BIA $T E$ values ( $T E<4.0 \%$ fat). Future research is needed to reevaluate the validity of previously-used equations and BIA devices compared to multiple-compartment models that utilize TBW. Furthermore, it appears that both BIA-AK and BIA-Lohman are acceptable field methods for estimating $\%$ fat in college men. However, the $95 \%$ limits of agreement suggest both BIA-AK and BIA-Lohman may overpredict \%fat by as much as 3.09 and $4.48 \%$ fat and underpredict by as much as 4.65 and $3.83 \%$ fat, respectively. These individual variations are most likely attributed to deviations in intra-cellular fluid which a single frequency (50-kHz) BIA device cannot detect. Therefore, caution should be used when relying on BIA alone as a method to identify \%fat in small groups or individuals.

\section{Circumference measurements}

The final aim of this study was to examine the validity of military circumference-based equations to estimate \%fat compared to both the 3C model and HW. In agreement with Clasey et al. [6] $(C E=4.2 \%$ fat $)$, who compared a similar circumference-based equation [49] to the $4 \mathrm{C}$ model in young men, our results indicated all equations underestimated ( $\mathrm{CE} \geq 1.86 \%$ fat) \%fat compared to the $3 \mathrm{C}$ model. Additionally, all equations produced unacceptable $T E$ values $>4.0 \%$ fat, which is similar to the reported TE (6.98\% fat) value by Clasey et al. [6]. To our knowledge, this is the first study to compare military circumference-based equations to the $3 \mathrm{C}$ model. However, the equations used in the current investigation have been previously validated against $H W$ in a similar population $[8,42]$. The current SEE values (SEE $=3.79-3.96 \%$ fat $)$ were greater when compared to the $3 \mathrm{C}$ than the findings of Friedl and Vogel [8], who compared the MC (SEE = $3.27 \%$ fat $), \operatorname{NAF}(S E E=3.13 \%$ fat $), A(S E E=3.15 \%$ fat $)$, and Friedl ( $S E E=3.10 \%$ fat) equations to DXA in male soldiers $(<40$ years, mean $\mathrm{BM}=77.4 \mathrm{~kg}, \mathrm{HT}=176.7 \mathrm{~cm})$. Additionally, all the $r$ values in the current investigation $(r$ $\leq 0.62$ ) were less than those reported by Friedl and Vogel [8] $(r \geq 0.80)$. Furthermore, Kremer et al. [42] compared the NAF equation to $\mathrm{HW}$ in Air Force members 18-47 years of age (mean body mass $=87.2 \mathrm{~kg}$, height $=178.5$ $\mathrm{cm}$ ) with contrary findings to the current investigation. Kremer et al. [42] found smaller a SEE (3.28\% fat) and TE (3.54\% fat) value and a larger $r(0.91)$ value than the present results $(S E E=3.96 \%$ fat, $T E=5.2 \%$ fat, $r=0.57)$. Therefore, all four circumference-based equations are not recommended for estimating \%fat in college-age men.

It was hypothesized that all four circumference-based equations would produce valid results when compared to HW. Contrary to our hypothesis, only the MC, A and Friedl equations produced acceptable TE values (TE $\leq$ 3.7). Conversely, all $T E$ values were $\geq 3.5 \%$ fat, which is sometimes classified as the minimal standard [7]. While the NAF equation was in closer agreement with the findings of Kremer et al. [42] (TE = 3.54\% fat), the TE value was still unacceptable ( $T E=4.1 \%$ fat $)$. Nonetheless, the study by Friedl and Vogel [8] produced comparable SEE values for the $\mathrm{MC}(S E E=3.27 \% \mathrm{fat}), \mathrm{A}(S E E=3.15 \% \mathrm{fat})$ and Friedl ( $S E E=3.10 \% \mathrm{fat}$ ) equation to the current investigation compared to HW (MC, SEE $=3.00 \%$ fat; A, $S E E=3.23 \%$ fat; Friedl, $S E E=3.15 \%$ fat $)$. In conclusion, the results of the current investigation suggest that military circumference-based equations are not valid methods to estimate the \%fat of college-age Caucasian men and are not recommended for use in this population.

\section{Conclusion}

Both 2C laboratory methods (BP, HW) produced acceptable TE values when compared to the $3 \mathrm{C}$ model of Siri [3]. However, due to the large limits of agreement, the use of $2 \mathrm{C}$ models may not be appropriate when attempting to identify and track \%fat in small groups or individuals due to the individual variations of a third compartment $[2,6,26]$. Wang et al. [2] determined that the 3C model used in the current investigation along with $4 \mathrm{C}$ models were some of the best methods to use as criteria \%fat esti- 
mates compared to the $6 \mathrm{C}$ model and concluded these $2 \mathrm{C}$ models (BP, HW) may not be appropriate across all age, sex, and disease groups for estimating \%fat. However, the current investigation provides data that validate the use of these 2C models (BP, HW) for use in college age males. Thus, caution should be used when utilizing one of these $2 \mathrm{C}$ models in a research setting when \%fat or other body composition compartments (fat-free mass, fat mass) are being estimated or tracked for small groups or individual college-age Caucasian men.

Limitations of the current study include the estimates of $\%$ fat from the 3C model. Since \%fat values from the $3 \mathrm{C}$ model included measurements from $\mathrm{HW}$, there could potentially be greater agreement between $\mathrm{HW}$ and the $3 \mathrm{C}$ model. Additionally, multiple-compartment models with greater complexity than the $3 \mathrm{C}$, such as the 4,5 and $6 \mathrm{C}$ models, are better criterion methods, and, thus, should be used to validate the methods included in the current study in this population. Furthermore, TBW measurements were obtained via BIS, which is a valid measure but not a criterion method. The possibility exists that the use of a criterion method, such as deuterium oxide, to measure TBW could influence the values found in the current investigation.

In summary, this study provides original data regarding the validity of laboratory and field methods. Our data suggest $\mathrm{BP}$ is an acceptable laboratory method to use when HW or multiple-compartment models are not available or subject compliance is a potential problem. Furthermore, our results indicate that BIA-AK, BIA-Lohman are valid alternatives to estimate \%fat when laboratory methods are unavailable for college-age Caucasian men. However, caution should be used when using NIR and military circumference-based equations to estimate \%fat in this population and are not recommended.

\section{Competing interests}

The authors declare that they have no competing interests.

\section{Authors' contributions}

JM, ST, JC, TB, and JS participated in the study design and helped draft the manuscript while aiding in data collection. AS, AW, CL, MR, ER, and VD participated in data collection and analysis. Additionally, all authors read and approved the final manuscript.

\section{Acknowledgements}

We would like to thank all the authors and Masaru Teramoto, Murat Karabulut, So Jung Kim, and Holly R. Hull for their contributions during the data collection and subject recruitment phases of this study.

\section{References}

I. Durnin JV, Womersley J: Body fat assessed from total body density and its estimation from skinfold thickness: measure- ments on $48 \mathrm{I}$ men and women aged from 16 to 72 years. The British journal of nutrition 1974, 32(1):77-97.

2. Wang ZM, Deurenberg P, Guo SS, Pietrobelli A, Wang J, Pierson RN Jr., Heymsfield SB: Six-compartment body composition model: inter-method comparisons of total body fat measurement. Int J Obes Relat Metab Disord 1998, 22(4):329-337.

3. Siri WE: Body composition from fluid spaces and density. Analysis of methods. In Techniques for Measuring Body Composition Edited by: Brozek J, Henschel A. Washington, DC, National Academy of Sciences; 1961:223-244.

4. Brozek J, Grande F, Anderson JT, Keys A: Densitometric Analysis of Body Composition: Revision of Some Quantitative Assumptions. Ann N Y Acad Sci 1963, I I 0: I I3- I 40.

5. Fuller NJ, Jebb SA, Laskey MA, Coward WA, Elia M: Four-component model for the assessment of body composition in humans: comparison with alternative methods, and evaluation of the density and hydration of fat-free mass. Clin Sci (Lond) 1992, 82(6):687-693.

6. Clasey JL, Kanaley JA, Wideman L, Heymsfield SB, Teates CD, Gutgesell ME, Thorner MO, Hartman ML, Weltman A: Validity of methods of body composition assessment in young and older men and women. J Appl Physiol 1999, 86(5): 1728-1738.

7. Heyward VH, Wagner DR: Applied Body Composition Assessments. Champaign, IL , Human Kinetics; 2004.

8. Friedl KE, Vogel JA: Validity of percent body fat predicted from circumferences: classification of men for weight control regulations. Military medicine 1997, 162(3): 194-200.

9. Moon JR, Hull HR, Tobkin SE, Teramoto M, Karabulut M, Roberts MD, Ryan ED, Kim SJ, Dalbo VJ, Walter AA, Smith AE, Cramer JT, Stout JR: Percent body fat estimations in college women using field and laboratory methods: a three-compartment model approach. J Int Soc Sports Nutr 2007, 4(I): 16.

10. Prior BM, Modlesky CM, Evans EM, Sloniger MA, Saunders MJ, Lewis $\mathrm{RD}$, Cureton $\mathrm{KJ}$ : Muscularity and the density of the fat-free mass in athletes. J Appl Physiol 200I, 90(4):I523-I53I.

II. Wilmore JH, Vodak PA, Parr RB, Girandola RN, Billing JE: Further simplification of a method for determination of residual lung volume. Med Sci Sports Exerc 1980, I 2(3):216-218.

12. Lohman TG: Advances in body composition assessment. Champaign, IL , Human Kinetics; 1992.

13. Matthie J, Zarowitz B, De Lorenzo A, Andreoli A, Katzarski K, Pan G, Withers P: Analytic assessment of the various bioimpedance methods used to estimate body water. J Appl Physiol 1998, 84(5): $|80|-18 \mid 6$.

14. Van Loan MD, Withers P, Matthie J, Mayclin PL: Use of bioimpedance spectroscopy to determine extracellular fluid, intracellular fluid, total body water, and fat-free mass. Basic Life Sciences 1993, 60:67-70.

15. Moon JR, Tobkin SE, Roberts MD, Dalbo VJ, Kerksick CM, Bemben MG, Cramer JT, Stout JR: Total body water estimations in healthy men and women using bioimpedance spectroscopy: a deuterium oxide comparison. Nutr Metab (Lond) 2008, 5(I):7.

16. Minderico CS, Silva AM, Keller K, Branco TL, Martins SS, Palmeira AL, Barata JT, Carnero EA, Rocha PM, Teixeira PJ, Sardinha LB: Usefulness of different techniques for measuring body composition changes during weight loss in overweight and obese women. The British journal of nutrition 2007:I-I0.

17. Sardinha LB, Silva AM, Teixeira PJ: Usefulness of age-adjusted equations to estimate body fat with air displacement Plethysmography in male adolescent athletes. Acta Diabetol 2003, 40(I):5I-55.

18. Wright HF, Dotson CO, Davis PO: A simple technique for measurement of percent body fat in man. U S 1981, 72(5):23-27.

19. Vogel JA, Kirkpatrick JW, al. FPI: Derivation of anthropometry based body fat equations for the Army's weight control program. Volume Technical Report TI7-88. Natick, MA, US Army Research Institute of Environmental Medicine; 1988.

20. Hodgdon JA, Beckett MB: Prediction of percent body fat for U.S. Navy men from body circumferences and height. Volume Report No. 84-II. San Diego, CA , Naval Health Research Center; 1984.

21. Siri WE: The gross composition of the body. Advances in biological and medical physics 1956, 4:239-280.

22. Wang ZM, Shen W, Withers RT, Heymsfield SB: Multicomponent molecular-level models of body composition analysis. In Human body composition 2nd edition. Edited by: Heymsfield SB, 
Lohman TG, Wang ZM, Going SB. Champaign, IL , Human Kinetics; 2005:163-176.

23. Keppel G, Wickens TD: Design and Analysis: A Researchers Handbook. 4th edition. Upper Saddle River, NJ , Prentice Hall; 2004.

24. Bland JM, Altman DG: Statistical methods for assessing agreement between two methods of clinical measurement. Lancet 1986, I(8476):307-310.

25. Visser M, Gallagher D, Deurenberg P, Wang J, Pierson RN, Heymsfield SB: Density of fat-free body mass: relationship with race, age, and level of body fatness. The American journal of physiology I 997, 272(5 Pt I):E78I-7.

26. Withers RT, LaForgia J, Pillans RK, Shipp NJ, Chatterton BE, Schultz $C G$, Leaney F: Comparisons of two-, three-, and four-compartment models of body composition analysis in men and women. J Appl Physiol 1998, 85(I):238-245.

27. Demerath EW, Guo SS, Chumlea WC, Towne B, Roche AF, Siervogel RM: Comparison of percent body fat estimates using air displacement plethysmography and hydrodensitometry in adults and children. Int J Obes Relat Metab Disord 2002, 26(3):389-397.

28. Biaggi RR, Vollman MW, Nies MA, Brener CE, Flakoll PJ, Levenhagen DK, Sun M, Karabulut Z, Chen KY: Comparison of air-displacement plethysmography with hydrostatic weighing and bioelectrical impedance analysis for the assessment of body composition in healthy adults. Am J Clin Nutr 1999, 69(5):898-903.

29. Levenhagen DK, Borel MJ, Welch DC, Piasecki JH, Piasecki DP, Chen $\mathrm{KY}$, Flakoll PJ: A comparison of air displacement plethysmography with three other techniques to determine body fat in healthy adults. J Parenter Enteral Nutr 1999, 23(5):293-299.

30. McCrory MA, Gomez TD, Bernauer EM, Mole PA: Evaluation of a new air displacement plethysmograph for measuring human body composition. Med Sci Sports Exerc 1995, 27( I 2): |686-I69I.

31. Piccoli A, Nigrelli S, Caberlotto A, Bottazzo S, Rossi B, Pillon L, Maggiore Q: Bivariate normal values of the bioelectrical impedance vector in adult and elderly populations. Am J Clin Nutr 1995, 61:269-2270

32. Conway JM, Norris KH, Bodwell CE: A new approach for the estimation of body composition: infrared interactance. Am J Clin Nutr 1984, 40(6): I I 23-I I 30.

33. Futrex I: Quality Systems Regulations: Futrex's internal Manual. Hagerstown, MD , Futrex, Inc; 2007.

34. Eckerson JM, Stout JR, Evetovich TK, Housh TJ, Johnson GO, Worrell $\mathrm{N}$ : Validity of Self-Assessment Tequniques for Estimating Percent Fat in Men and Women. J Strength and Cond Res 1998, 1 2(4):243-247.

35. Israel RG, Houmard JA, O'Brien KF, McCammon MR, Zamora BS, Eaton AW: Validity of a near-infrared spectrophotometry device for estimating human body composition. Res $Q$ Exerc Sport 1989, 60(4):379-383.

36. McLean KP, Skinner JS: Validity of Futrex-5000 for body composition determination. Med Sci Sports Exerc 1992, 24(2):253-258.

37. Stout JR, Eckerson JM, Housh TJ, Johnson GO, Betts NM: Validity of percent body fat estimations in males. Med Sci Sports Exerc 1994, 26(5):632-636.

38. Vehrs P, Morrow JR Jr., Butte N: Reliability and concurrent validity of Futrex and bioelectrical impedance. International journal of sports medicine 1998, 19(8):560-566.

39. Eckerson JM, Housh TJ, Johnson GO: Validity of bioelectrical impedance equations for estimating fat-free weight in lean males. Med Sci Sports Exerc 1992, 24(I I): I298-I 302.

40. Eckerson JM, Housh TJ, Johnson GO: The validity of visual estimations of percent body fat in lean males. Med Sci Sports Exerc 1992, 24(5):615-618.

4I. Eckerson JM, Stout JR, Housh TJ, Johnson GO: Validity of bioelectrical impedance equations for estimating percent fat in males. Med Sci Sports Exerc 1996, 28(4):523-530.

42. Kremer MM, Latin RW, Berg KE, Stanek K: Validity of bioelectrical impedance analysis to measure body fat in Air Force members. Military medicine 1998, I63(I I):78|-785.

43. Jackson AS, Pollock ML, Graves JE, Mahar MT: Reliability and validity of bioelectrical impedance in determining body composition. J Appl Physiol 1988, 64(2):529-534.
44. Lukaski HC, Bolonchuk WW, Hall CB, Siders WA: Validation of tetrapolar bioelectrical impedance method to assess human body composition. J Appl Physiol 1986, 60(4): I327-I332.

45. Segal KR, Van Loan M, Fitzgerald PI, Hodgdon JA, Van Itallie TB: Lean body mass estimation by bioelectrical impedance analysis: a four-site cross-validation study. Am J Clin Nutr 1988, 47(I):7-14.

46. Thomasett A: Bio-electrical properties of tissue impedance measurements. Lyon Medical 1962, 207:107-II8.

47. Wang Z, Deurenberg P, Wang W, Pietrobelli A, Baumgartner RN, Heymsfield SB: Hydration of fat-free body mass: review and critique of a classic body-composition constant. Am J Clin Nutr 1999, 69(5):833-84|.

48. Barbosa-Silva MCG, Barros AJD: Bioelectrical impedance analysis in clinical practice: a new perspective on its use beyond body composition equations. Curr Opin Clin Nutr Metab 2005, 8:3II-3I7.

49. Tran ZV, Weltman A: Predicting body composition of men from girth measurements. Human biology; an international record of research 1988, 60(1):167-175.
Publish with Bio Med Central and every scientist can read your work free of charge

"BioMed Central will be the most significant development for disseminating the results of biomedical research in our lifetime. "

Sir Paul Nurse, Cancer Research UK

Your research papers will be:

- available free of charge to the entire biomedical community

- peer reviewed and published immediately upon acceptance

- cited in PubMed and archived on PubMed Central

- yours - you keep the copyright

Submit your manuscript here:

http://www.biomedcentral.com/info/publishing_adv.asp
BioMedcentral 